Sportive culture related to the educational Environment and its Relationship to social interaction for the students at the Faculty of Physical Education in the New Valley *Dr/ Bahy Ahmad Mahmoud Abdulnaeem *** Dr/ Abu Bakr Muhammad Morsi

Introduction and research problem:

Culture is the mirror of society, which expresses its development and distinguishes it from other societies. It reflects the heritage of society, its values and beliefs, its history and the intellectual and cultural level of individuals in it. Sportive culture is an integral part of the general culture and no less important than other cultures in the society such as healthy, educational and social education .

Sportive culture also has an effective role in spreading and instilling the principles of sportsmen among students, as well as spreading awareness and blocking unwanted behavior. The sportive culture in the modern concept has exceeded the physical concept of research to include psychological, ethical, aesthetic, recreational and cultural concepts and it is an important means of deepening the relationship of the citizen with his home and actual life, as what has been previously mentioned is not done spontaneously but in a programmed manner both in schools or colleges or from $\mathrm{TV}$, newspapers, radio, cinema or festivals. The ultimate goal is to educate the citizen culturally (10:pp.20 -21).

Giving interest to the surrounding environment and preservation it from all that surrounds and threats it is inevitable and closely linked to human life because all components of the environment, including living

Football lecturer at the Department of Curricula \&methodology of physical education, Faculty of Physical Education, New Valley Branch, Assiut University.

"* Basketball Lecturer at the Department of Curricula \&methodology of physical education, Faculty of Physical Education, New Valley Branch, Assiut University the Department of Curriculum and Physical Education teaching-Faculty of Physical Education, New Valley Branch, Assiut University 
organisms, plants and inanimate objects, interact with each other and affect each other, and any component of the environment negatively affects human life. (3:p.2).

Therefore, an individual's recognition of the importance of the environment since ancient times, but since the existence of man on the Earth has the greatest impact and importance, as its aim was to; educate human aware behavior and to translate it into educational and behavioral objectives which are transformed into learning experiences for human life to become apparent in his practice and rational behavior toward the environment. Consequently, the individual must receive during his education what makes him recognize the dangers surrounding the environment and learn how to protect and preserve it in order to guarantee for us the assured protection from the environment surrounding us (5:81).

The importance of research lies in the following considerations:
Stimulating knowledge frames and raising interest to broaden the circle of human aspect associated with sport.

The founding of the theoretical aspect of sport and recreation and establishing aspect structure of the academic system.

Increasing the awareness of giving interest to the impact of the physical activity on various aspects of human personality.

Forming and building recreational and sportive interests and trends based on the correct and established aspect bases (8:256).

As a result, the the environment enhances many behavioral activities, especially the sportive ones which include cooperation, love, brotherhood, self-fulfillment, respect for the rights of others are achieved during playing. The desire to win makes the individual exert effort, and thus valuable human relations, collective awareness and cooperative coexistence are instilled in individuals. To be developed socially, student must learn the rules of social behaviors, his role in social life and social development. These basic components consist of two phases which are not 
separated from each other: selfdevelopment and development of social reaction and dealing with others. The individual and others' actions in social attitudes are sensory, and their influence is direct, and often the reaction is innate. The social skills here play a big role and this is a point that has to do with the growth of abilities. The student must feel his personal emotions and emotions of others and understand them. (13:148)

With the attention given by the State to sportive and environmental issues through Sustainable Development strategy: vision of Egypt 2030, the focus should be on developing the curricula at the faculties of physical education and raising the slogan of curricula development in order to solve problems and issues of society, to develop sportive and environmental awareness and to instill positive values and behavioral controls for the students. This will be reflected on the students at the Faculty of Physical Education through their preservation of the environment and contribution to the service of the
Community and solving its problems.

"Ikhlas Mohamed Abdel Hafeez and Mustafa Hussein Bahy (2001) agree with each other in the point that the process of social interaction helps individual to acquire and learn about his roles and the acquisition of social norms in the light of the socialization process which in turn helps him to acquire the psychological trends through which the individual learns how he/she behaves and reacts in a social way. (1:37)

The faculties of Physical education are one of the most important educational institutions within the Egyptian universities. It is the source of sportive leadership, which prepares human cadres in an integrated way to be capable of achieving the modern educational goals of contemporary society through specialized programs that qualify graduates to perform many tasks and responsibilities (9:1).

While highlighting the importance of this vital aspect for the students at the Faculty of Physical Education has an impact on the awareness of 
students and their attitudes toward the sportive issues related to environment in Egyptian society, which will help them to transfer the positive image of the environment to the learners in Educational stages; there is now great interest given to sportive issues related to environment at various educational institutions. (15:152-153).

Therefore, the sportive culture related to environment is one of the main cognitive and basic aspects in teaching physical education and imparting aspect and information to students, as it is a practice that is popular among all people at different cultural, social and age levels. They contribute to finding a fit human being in sportive, healthy and social aspects.

Through the work of the two researchers as faculty members at the Faculty of Physical Education, New Valley Branch, Assiut university, and through the academic sessions and debates done at the faculty, they have noted that there is a significant weakness in the level of sportive culture related to environment among students at the Faculty of Physical Education, which may have a negative impact on the social interaction among them. Based on the importance of practicing activities in the educational process, the two researchers see that there is the need to improve the cultural and sportive aspect for the students at the Faculty of Physical education, and this can be done by spreading the cultural, sportive and environment awareness so that students can participate at sportive activities related to environment of all kinds inside university and outside it. This can be helpful in investing in their energies on leisure time away from the practice of destructive activities. By investigating the reports related to the activities offered to the students of the faculty by the youth care office, it was shown that there is not tendencies toward these activities, although the two researchers have noticed the presence of students in large numbers outside the lecture halls or stadiums. This indicates that those students have leisure time which should be invested better. We must offer programs and information 
which enhance the sportive culture related to environment at the stage of academic preparation of the student teacher to improve the level of sportive culture related to environment at all aspects. The students have to develop the sportive awareness to produce a socially interacted generation .

\section{Significance of research:}

The current research may contribute to:

-Designing a scale of sportive culture related to educational environment for students at the Faculty of Physical Education, New Valley Branch, Assiut University.

-Building a scale of social interaction for students at the Faculty of Physical Education, New Valley branch, Assiut University.

- promoting the cultural, sportive and environmental awareness among students.

-Developing the social interaction for students .

\section{Research objectives:}

The current research aims at:

Identifying the differences in the level of sportive culture related to educational environment among students at the Faculty of Physical
Education, New Valley branch, Assiut University

Identifying the differences in the level of social interaction among the students at the Faculty of Physical Education,New Valley branch, Assiut university

Identifying the relationship between the level of sportive culture related to educational environment and social interaction among the students at the Faculty of Physical Education, New Valley branch, Assiut university.

\section{Research Hypotheses:}

In the light of the research objectives, the two researchers have presented the following hypotheses:

There are statistically significant differences in the level of sportive culture related to educational environment among the students at the Faculty of Physical Education, New Valley branch, Assiut university.

There are statistically significant differences in the level of social interaction among the students at the Faculty of Physical Education, New Valley branch, Assiut university. 
There is a statistically significant relationship between the level of sportive culture related to educational environment and social interaction among the students at the Faculty of Physical Education, New Valley branch, Assiut university.

\section{Research Terms:}

"Sportive culture ", Sportive Culture:is "The abundance of human expertise through sportive activities, which in turn leads to better understanding and appreciation of the environment in which individuals find themselves a part" (6:77).

Sportive culture related to educational environment "is the cognitive experience related to practicing the available sportive activities in the givings of the educational environment

(lecturesmeetings- forums- workshops) (procedural concept).

"Social interaction":

It is" the relational behavior that exists among individual and a group of individuals in different social situations, as social interaction, in its broadest sense, is influenced by the behaviors, actions, performance of others in the sense that there is influence, impact, action and emotion in any situation. (4:88).

\section{Related studies:}

The

research

of

"Muhammad Hosni Zein alAbidin Ahmed (2016) (15) entitled" The Impact of sportive culture on the promotion of the values of national affiliation in juvenile delinquents ".The research has aimed at determining the effectiveness of a program of sportive culture to promote the values of national belonging for juvenile delinquents. The researcher used the experimental method designed for one group. The research sample was chosen in the intentional manner as the total sample of research was seventy Child from juvenile delinquent care institutions and they were under the age of (18) years. Data collection tools were represented in the corresponding personal interview and a poll form presented to the experts opinion. Among the most important findings of the research was that the sportive culture promotes the values of national belonging for juvenile delinquents . 
The research of "Honda Ali Ali (2013) (17) entitled "Social Interaction and its relationship to the educational achievement of some secondary school pupils" .The research aimed at identifying the nature of the relationship between the school social interaction (pupilmanagement/pupil-teacher/ pupil-Fellows) and the academic achievement of pupils at the third year of secondary education.The researcher used the relational descriptive method. The sample of the research was represented in the third grade pupils whose number was (115) pupil from the research community $(2300$ with a percentage $(50 \%)$. Data collection tool were the questionnaire and the personal interview. Among the most important findings of the researcher were that there was a statistically significant correlation between the school social interaction and school attainment for students who are at the third grade of secondary education.

The research of "Salah Mohammed Abdul Baset Mohammed (2010) entitled" The Effectiveness of the program of sportive activity and health culture on the physical fitness and healthy behavior for juvenile delinquents in Assiut Governorate "The research aimed at designing a program of sportive activity and health culture on the elements of fitness associated with healthy behavior. The researcher used the descriptive method using survey studies and the onegroup experimental method due to the need for the research. The sample was chosen in the intentional manner of juvenile delinquents whose number was sixty (60) person from the care of juveniles in Assiut Governorate, and their ages ranged from twelve to fifteen 15 years ago. Data collection tools and data collection forms were data gathering form and measurement devices .One of the most important results is that the proposed sportive activity and health culture program has led to an improvement in the level of health-related fitness and the high level of healthy behavior of the sample .

The research of Osman Mahmoud Shaahaza (2009) (8) 
entitled "The Impact of watching sportive satellite channels in the dissemination of sportive culture among the students of Deyali university". The research aimed at; designing a measure of sportive culture for the viewers of satellite sportive channels and identifying the impact of watching sportive satellite channels on disseminating sportive culture among students of the university of Deyali. The researcher used the descriptive method using survey studies. The sample was chosen in a random way from the university students where the total sample of research were (190) student and of them, (75) Students were chosen with a percent $(39.47 \%)$. The data collection tools were measure instruments, forms and personal interview. One of the most important results of the research was that the measure of the sportive culture designed for the viewers of the sportive satellite channels fitted the selected sample, and that the sportive satellite channels have a positive effect on providing the viewer with sportive culture.
The research of Shine "Chen" (2010) (18): entitled The Impact of Sportive activities on the sportive identity and the commitment of sportive students and ordinary athletes at the institutions of Physical Education in Ohio. The research aimed at knowing the impact of the e sportive activities exercise on the sportive identity and commitment .The sample of the research consisted of (275) students who were distributed in two groups. The first group included sports students who exercise their sportive games at the National League for University Sports, and the second group included ordinary sports students who are only practicing sports at Physical education institutes. One of the most important findings of the research was that the level of sportive identity and commitment of the first group was better than the second group, and there were statistically significant differences in sportive identity between males and females in favor of males in both groups.

The research of Frasser "Fraser" (2009) (19): entitled "The level of Sportive identity

\section{Assiut Journal For Sport Science Arts}


of elite sportsmen in Australia". The research aimed at determining the level of sportive identity of the elite sportsmens in Australia, in addition to determining the impact of sex, age and professional status on the sportive identity. To achieve this, the research was conducted on a sample of 426 male and female players who won sports scholarships from the Australian sports Institute. Among the most important results of the research was that the level of the sportive identity for those players was high. There were differences in sportive identity depending on the variables of sex, age, and occupational status, as the differences were in favor of males and the young. As for the occupational status, the results showed that the level of identity is lower for the retired players.

\section{Research procedures: \\ Research methodology:} plan and

The researchers used the descriptive approach in the survey method as it suits the nature of the research.

Research community:
The research community is represented by the students of the third and Fourth Division (Teaching Specilaization) at the Faculty of Physical Education in the new Valley branch, Assiut University with a total of (149) Students for the academic year 2016/2017 AD.

\section{Research Sample:}

The sample was chosen in a random manner covering sixty student representing the basic sample of the research The expiatory sapmle included ten Students with a percent $(46.27 \%)$ of research community whose number is (149) male and female student..

\section{Data collection Tools:}

Personal interviews

Scale of the Sportive culture related to educational environment (prepared by the two researchers)

Social interaction scale (researchers ' numbers prepared by the two researchers).

\section{Field research procedure:}

First: Building the scale of sportive culture related to educational environment:

Because of many practices of the educational environment at faculty, which were stemmed from many sportive activities 
related to educational environment such as workshops, seminars, meetings, lectures and conferences, upon which many aspects related to sportive culture have emerged. So, the researchers seek to design the scale as follows:

- The Steps to build the scale:

-A Opinion poll form presented to the experts to express their views on designing the scale of sportive culture related to educational environment among students at the Faculty of Physical Education, New Valley branch, Assiut university.

The researchers used several scientific references that addressed the methods of evaluation, tests and objective measurements, namely "Ikhlas Mohamed Abdel Hafeez, Mustafa Hussein Bahy" (2002) (2), "Qasim Ali al-Sarraf" (2004) (12), "Mohamed Sobhi Hasaneen " (2000) (16), "Fadi Fattouh Ahmad ",through which the following steps have been reached out to construct the scale:

\section{Determining the purpose of the scale:}

In the light of the sportive culture related to educational environment, the goal of the scale has been defined and represented in the dissemination of cultural, sportive and environmental awareness. The suitability of the scale to the age level of the research sample

\section{Determining the axes of}

\section{the scale:}

To determine the axes, the researchers used the following sources:

specialized references and studies:

The researchers analyzed some of the specialized references in the field of tests, measurements and sportive media (2), (3), (5), (6), (7),(8), (16) which handled the spread and increase of cultural and environmental awareness . The two researchers have reached out the axes of the scale as it is explained in annex (2).

\section{B-Experts:}

The two researchers prepared the experts'opinion poll form(annex(2) on 9/1/2016 which included five axes identified through the reference survey, and this form was presented to the experts to determine the most important 
of these axes Annex (1) and table (1) explain this:

Table (1) shows

Experts' opinions to determine the basic axes of the Sportive culture related to educational environment scale $(n=10)$

\begin{tabular}{c|c|c|c|c|c}
\hline \hline S & Suggested axes & \multicolumn{2}{|c|}{ Expert's opinion } & Estimated & percentage \\
\cline { 3 - 5 } & Suitable & $\begin{array}{c}\text { Not } \\
\text { suitable }\end{array}$ & & \\
\hline \hline 1 & Sportive Aspect & 9 & 1 & 18 & $90 \%$ \\
\hline 2 & $\begin{array}{c}\text { educational } \\
\text { aspect }\end{array}$ & 8 & 2 & 16 & $80 \%$ \\
\hline 3 & Health aspect & 8 & 2 & 16 & $80 \%$ \\
\hline 4 & $\begin{array}{c}\text { Environmental } \\
\text { aspect }\end{array}$ & 7 & 3 & 14 & $70 \%$ \\
\hline 5 & $\begin{array}{c}\text { Sportive } \\
\text { Touristic aspect }\end{array}$ & 5 & 5 & 10 & $50 \%$ \\
\hline \hline
\end{tabular}

It is clear from table (1) that the percentage of experts' opinions ranged from $50 \%$ to 90\%. The researchers accept the choice of axes that obtained (70\% and more). The axes that got a lower percentage were excluded so that the number of axes of the scale was four axes represented in: sportive aspect, educational aspect, healthy aspect, and environmental aspect.

-the necessary modifications referred to by the experts in terms of the correct linguistic and technical formulation in the axes of the scale were done, and the final version of the form is shown in annex (3).
3- Preparing the language of the Sportive culture related to educational environment scale:

In the light of the achievement of the objective of the research, and depending on the aspect of scientific references, research and studies, the design of the terms and of the form have been taken into account to lead to accurate data and the phrases and should be simple, easy, and understandable and formulated in a proper linguistic way. They shouldn't be complex as they carry more than one meaning so that they cannot cause overlap and achieve the goal for which they 
were developed. The researchers drafted the Sportive culture related to educational environment scale in its initial form(annex(4), which was presented to experts on $18 / 1 / 2016$, and it included (63) phrases. There were (18) phrases at the axis of sportive aspect, (15) phrases at the environmental aspect axis, (15) phrases at the healthy aspect axis, and (15) at the axis of educational aspect.

The following points were taken into account in formulating the phrases:

A. Each phrase should measure a particular outcome linked to the main axis.

B- They suit the age level and the sample level.

They should be comprehensive, accurate, clear; simple. Table (2) illustrates this:

Table (2) shows

The percentages of experts' opinions about the phrases of the sportive culture scale

\begin{tabular}{c|c|c|c|c|c}
\hline \hline S & axes & \multicolumn{2}{|c|}{ Phrases } & Phrases & $\begin{array}{c}\text { Proportional } \\
\text { significance }\end{array}$ \\
\cline { 3 - 6 } & & Main & omitted & number & (13 \\
\hline \hline 1 & Sportive Aspect & 18 & 5 & 13 & $27.08 \%$ \\
\hline 2 & Environmental aspect & 15 & 3 & 12 & $25 \%$ \\
\hline 3 & Health aspect & 15 & 4 & 11 & $22.91 \%$ \\
\hline 4 & Educational aspect & 15 & 3 & 12 & $25 \%$ \\
\hline \hline
\end{tabular}

It is clear from table (2) that fifteen phrases were excluded according to the percentage of experts' opinions about the terms of the scale, and thus, the number of phrases of the measure of sportive culture related to educational environment is (48) term as it is shown in attached (5).

- scientific Coefficients of the scale:
-First: validity: The validity of the form has been confirmed in several ways to measure validity through:

\section{-The validity of the peer}

\section{reviewers:}

The form has been presented to ten experts at the Faculties of Physical education and faculties of education in order to poll their opinions on; the validity of this form regarding its suitability for students in 
terms of the clarity and integrity of phrases and formulation, in addition to making sure of the phrases and suitability with the objective of the form, with deleting, or modifying or adding what they see appropriate of phrases .The number of form phrases was (63) as it is shown in annex (4). The percentage of experts'opinions about the correct of the form has been calculated.

The necessary amendments referred by the experts in terms of appropriate linguistic and technical formulation or the omission of certain phrases have been made so that the number of scale phrases was (48) as illustrated in Table (3) :

\section{Table (3) shows}

The percentages of the phrases of the Sportive culture related to educational environment scale according to experts' opinions $n=(10)$

\begin{tabular}{|c|c|c|c|c|c|c|c|}
\hline \multicolumn{2}{|c|}{ Sportive Aspect } & \multicolumn{2}{|c|}{$\begin{array}{c}\text { Environmental } \\
\text { aspect }\end{array}$} & \multicolumn{2}{|c|}{ Health aspect } & \multicolumn{2}{|c|}{$\begin{array}{c}\text { educational } \\
\text { Aspect }\end{array}$} \\
\hline $\begin{array}{l}\text { Phrase } \\
\text { No. }\end{array}$ & Percentage & $\begin{array}{c}\text { Phrase } \\
\text { No. }\end{array}$ & percentage & $\begin{array}{l}\text { Phrase } \\
\text { No. }\end{array}$ & percentage & $\begin{array}{c}\text { Phrase } \\
\text { No. }\end{array}$ & percent: \\
\hline 1 & $100 \%$ & 1 & $100 \%$ & 1 & $100 \%$ & 1 & $100 \%$ \\
\hline 2 & $100 \%$ & 2 & $90 \%$ & 2 & $100 \%$ & 2 & $100 \%$ \\
\hline 3 & $80 \%$ & 3 & $80 \%$ & 3 & $90 \%$ & 3 & $90 \%$ \\
\hline 4 & $90 \%$ & 4 & $90 \%$ & 4 & $90 \%$ & 4 & $90 \%$ \\
\hline 5 & $80 \%$ & 5 & $90 \%$ & 5 & $80 \%$ & 5 & $80 \%$ \\
\hline 6 & $90 \%$ & 6 & $70 \%$ & 6 & $70 \%$ & 6 & $80 \%$ \\
\hline 7 & $70 \%$ & 7 & $80 \%$ & 7 & $80 \%$ & 7 & $80 \%$ \\
\hline 8 & $90 \%$ & 8 & $70 \%$ & 8 & $80 \%$ & 8 & $90 \%$ \\
\hline 9 & $80 \%$ & 9 & $70 \%$ & 9 & $80 \%$ & 9 & $70 \%$ \\
\hline 10 & $70 \%$ & 10 & $80 \%$ & 10 & $70 \%$ & 10 & $70 \%$ \\
\hline 11 & $70 \%$ & 11 & $70 \%$ & 11 & $90 \%$ & 11 & $70 \%$ \\
\hline 12 & $80 \%$ & 12 & $90 \%$ & - & - & 12 & $70 \%$ \\
\hline 13 & $90 \%$ & - & - & - & - & - & - \\
\hline \multirow[t]{2}{*}{$\begin{array}{l}\text { (3) } \\
\text { exp } \\
70^{c} \\
\text { the }\end{array}$} & \multicolumn{3}{|c|}{$\begin{array}{l}\text { It is obvious from table } \\
\text { that the percentage of } \\
\text { erts'opinions ranged from } \\
\text { to } 100 \text {, and this indicates } \\
\text { content validity of the }\end{array}$} & \multicolumn{4}{|c|}{$\begin{array}{l}\text { Sportive culture related to } \\
\text { educational environment scale. } \\
\text {-Internal consistency } \\
\text { validity: } \\
\text { The researchers applied the } \\
\text { scale on } 18 / 2 / 2016 \text { upon an }\end{array}$} \\
\hline & \multicolumn{4}{|c|}{ Assiut Journal For Sport Science Arts } & & & \\
\hline
\end{tabular}


exploratory group consisting of ten Students enrolled in the academic year (2016-2017) from outside the basic research sample in order to obtain accurate answers and to identify:

- The clarity of the scale phrases for students.

- Difficulties facing students when answering the scale paragraphs .

\section{Table (4) shows \\ correlation coefficients among axes phrases and the axis total} score $n=(10)$

\begin{tabular}{|c|c|c|c|c|c|c|c|}
\hline \multicolumn{2}{|c|}{ Sportive Aspect } & \multicolumn{2}{|c|}{ Environmental aspect } & \multicolumn{2}{|c|}{ Healthy aspect } & \multicolumn{2}{|c|}{ Educational Aspect } \\
\hline $\begin{array}{c}\text { Phrase } \\
\text { No. }\end{array}$ & $\begin{array}{c}\text { Correlation } \\
\text { coefficient }\end{array}$ & $\begin{array}{c}\text { Phrase } \\
\text { No. }\end{array}$ & $\begin{array}{c}\text { Correlation } \\
\text { coefficient }\end{array}$ & $\begin{array}{c}\text { Phrase } \\
\text { No. }\end{array}$ & $\begin{array}{c}\text { Correlation } \\
\text { coefficient }\end{array}$ & $\begin{array}{c}\text { Phrase } \\
\text { No. }\end{array}$ & $\begin{array}{c}\text { Correlation } \\
\text { coefficient }\end{array}$ \\
\hline 1 & $0.92 *$ & 1 & $0.65 *$ & 1 & $0.66 *$ & 1 & $0.69 *$ \\
\hline 2 & $0.70 *$ & 2 & $0.55 *$ & 2 & $0.65 *$ & 2 & $0.77 *$ \\
\hline 3 & $0.51 *$ & 3 & $0.70 *$ & 3 & $0.61 *$ & 3 & $0.66 *$ \\
\hline 4 & $0.64 *$ & 4 & $0.55 *$ & 4 & 0,58 & 4 & $0.92 *$ \\
\hline 5 & $0.55 *$ & 5 & $0.52 *$ & 5 & $0.66 *$ & 5 & $0.74 *$ \\
\hline 6 & $0.70 *$ & 6 & $0.65 *$ & 6 & $0.61 *$ & 6 & $0.70 *$ \\
\hline 7 & $0.55 *$ & 7 & $0.55 *$ & 7 & $0.55 *$ & 7 & $0.90 *$ \\
\hline 8 & $0.52 *$ & 8 & $0.82 *$ & 8 & $0.66 *$ & 8 & $0.66 *$ \\
\hline 9 & $0.55 *$ & 9 & $0.71 *$ & 9 & $0.55 *$ & 9 & $0.95 *$ \\
\hline 10 & $76 *$ & 10 & $0.52 *$ & 10 & $0.61 *$ & 10 & $0.70 *$ \\
\hline 11 & $0.52 *$ & 11 & $0.93 *$ & 11 & $0.69 *$ & 11 & $0.55 *$ \\
\hline 12 & $0.69 *$ & 12 & $0.6^{*}$ & - & - & 12 & $0.74 *$ \\
\hline 13 & $0.64 *$ & - & - & - & - & - & - \\
\hline
\end{tabular}

The value of $r$ table at level $(0.05)=(0.497)$

Table (4) shows that there is a statistically significant correlation at $(0.05)$ level between the score of each

Table (5)

phrase at the axis and the overall score of the axis indicating the validity of internal consistency correlation coefficients among the phrases and their axes as well as correlation coefficients among axes and the total score of the scale were calculated as shown in the table (4):

- Identifying the time spent by each student to answer the phrases.

The 


\begin{tabular}{c|c}
\hline \multicolumn{2}{c}{ axes } \\
\hline \hline \multicolumn{2}{c|}{$\begin{array}{c}\text { Pearson correlation } \\
\text { coefficient }\end{array}$} \\
\hline \hline The first axis : sportive aspect & $0.62^{*}$ \\
\hline The second axis: environmental aspect & $0.64^{*}$ \\
\hline Third Axis: Health aspect & $0.63^{*}$ \\
\hline Fourth Axis :educational aspect & $0.65^{*}$ \\
\hline Scale as a whole & $0.72^{*}$ \\
\hline \hline
\end{tabular}

The value of $r$ table at $(0.05)$ level $=(0.497)$

Table (5) shows a The sportive culture related to statistically significant educational environment scale correlation at (0.05) level was applied on 18/2/2016 upon between the scale axes and the an exploratory sample score of the scale as a whole consisting of ten students from indicating the validity of the research community and internal consistency. outside the basic sample of Second: Stability of the research to find the stability scale:

-The method of stability of coefficient via the method of alpha as shown in table (6): alpha Cronbach:

Table (6) shows

Alpha cronbach's persistence coefficient for the Sportive culture related to educational environment scale

\begin{tabular}{c|c|c}
\hline \hline $\mathbf{S}$ & Axes & $\begin{array}{c}\text { Alpha Cronbach } \\
\text { coefficient }\end{array}$ \\
\hline \hline & The first axis : sportive aspect & 0.73 \\
\hline & The second axis: environmental aspect & 0.68 \\
\hline & Third Axis: Healthy aspect & 0.64 \\
\hline & Fourth Axis :educational aspect & 0.62 \\
\hline & Scale as a whole & $0.66 *$ \\
\hline
\end{tabular}

It is clear from Table (6) that the value of the stability coefficient of the axes ranges from 0.62 to 0.73 , and the persistence coefficient of the scale as a whole is equal to (0.66), and this the stability of the scale.

The method of reapplication: 
The two researchers applied the sportive culture related to educational environment scale on 18/2/2016 upon an exploratory sample consisting of ten students from the research community and outside the basic sample of research, and reapplication was carried out after two weeks on $3 / 3 / 2016 \mathrm{~m}$ and the correlation coefficient between the two applications was done as shown in table(7):

\section{table (7) shows}

Pearson coefficient between the two applications for the sportive culture related to educational environment scale

\begin{tabular}{c|c|c}
\hline \hline $\mathbf{S}$ & Axes & Pearson coefficient values \\
\hline \hline & The first axis : sportive aspect & 0.85 \\
\hline & The second axis: environmental aspect & 0.74 \\
\hline & Third Axis: Healthy aspect & 0.72 \\
\hline & Fourth Axis :educational aspect & 0.70 \\
\hline & Scale as a whole & $0.75 *$ \\
\hline \hline
\end{tabular}

It is clear from table (7) that there is increase of the stability coefficient between the two applications as the values ranged from $(0,70-0$, $85)$, and this refers to the acceptance of the tool to be applied.

-Grades estimates and correction method:

Grades $(1,2,3)$ are placed to correspond to the rankings (agree - to some extent - don't agree) with the attitude toward sportive culture related to educational environment, and the grades (1-2-3) with a weak attitude toward sportive culture related to educational environment . The multiple grades are combined plus the phrases of each axis to give the axis score. The total mark of the scale consists of the score of the four axes marks of the scale so that the highest score can be obtained in the scale is (144) mark and the lowest mark is (48) as shown in table (7):

Table (8)shows

Triple estimation measure of the Sportive culture related to educational environment scale 


\begin{tabular}{c|c|c|c}
\hline \hline S & Agree & $\begin{array}{c}\text { To some } \\
\text { extent }\end{array}$ & $\begin{array}{c}\text { Do not } \\
\text { agree }\end{array}$ \\
\hline \hline Phrases in the direction of the dimension & 3 & 2 & 1 \\
\hline Phrases in opposite of the dimension & 1 & 2 & 3 \\
\hline \hline
\end{tabular}

Scale time Defining:

The two researchers determined the appropriate time to answer the scale in light of the results of the application on the number of ten students enrolled at the Faculty of Physical Education, New Valley branch, Assiut University and outside the basic research sample from the following equation:

Scale time $=$ time spent by the first student $(20 \mathrm{~mm})+$ time spent by the last student (30m)

Thus, The total time of the scale was 25 minutes .

Second: Designing the scale of social interaction:

-Steps to design the scale:

-Experts' opinion poll form on designing the social interaction scale for students at the Faculty of Physical Education, New Valley branch, Assiut University.

The researchers used many academic references which handled the methods of evaluation, tests and objective scales such as "Ikhlas
Mohamed Abdel Hafeez, Mustafa Hussein Bahy " (2002) (2), "Qasim Ali al-Sarraf" (2004), (12), "Mohamed Sobhi hasaneen " (2000) (16), "Fadi Fattouh Ahmed"(2011) (11).

Upon these sources, the two researchers have reached out the following steps to design the scale:

-Determining the purpose of the scale:

In the light of social interaction, the objective of the scale was represented in measuring social interaction. It was taken into consideration the scale suitability to age level of research sample.

-Defining the axes of the scale:

To determine the axes, the two researchers used the following sources:

Specialized references and studies:

The researchers analyzed some of the specialized references and studies (1), (2), (14),(16),(17) in the field of tests, measurements and 
psychology that addressed the development of social interaction and its relationship to the sportive culture related to educational environment in particular. The two researchers have come down to the five axes of the scale which are communication, prediction, recognition of the role and its representation, symbols with significance, taking care of others .

\section{B-Experts:}

The researchers prepared experts' poll form annex(7) on 9/1/2016 which consisted of five axes identified by the reference survey. These axes were presented to the experts to determine the most important of these axes Annex (1), and table (9) illustrates this:

\section{Table (9) shows}

\section{Experts'opinions to determine the basic axes of the social} interaction scale $(n=10)$

\begin{tabular}{|c|c|c|c|c|c|}
\hline \multirow[t]{2}{*}{$\bar{S}$} & \multirow[t]{2}{*}{ Suggested axes } & \multicolumn{2}{|c|}{ Expert's opinion } & \multirow{2}{*}{$\begin{array}{l}\text { Estimated } \\
\text { mark }\end{array}$} & \multirow[t]{2}{*}{ percentage } \\
\hline & & Suitable & $\begin{array}{c}\text { Not } \\
\text { suitable }\end{array}$ & & \\
\hline 1 & Communication & 9 & 1 & 18 & $90 \%$ \\
\hline 2 & Prediction & 7 & 3 & 14 & $70 \%$ \\
\hline 3 & $\begin{array}{l}\text { The focus of role } \\
\text { recognition and its } \\
\text { representation }\end{array}$ & 5 & 5 & 10 & $50 \%$ \\
\hline 4 & Significant Symbols & 4 & 6 & 8 & $40 \%$ \\
\hline 5 & $\begin{array}{l}\text { taking caring of } \\
\text { others }\end{array}$ & 7 & 3 & 14 & $70 \%$ \\
\hline \multicolumn{3}{|c|}{$\begin{array}{l}\text { Table (9) shows that the } \\
\text { percentage of experts' opinions } \\
\text { ranged from } 40 \% \text { to } 90 \% \text {. The } \\
\text { researchers have accepted the } \\
\text { choice of the axes that scored } \\
\text { up to ( } 70 \%) \text {. The axes that } \\
\text { scored a lower percentage were } \\
\text { excluded, and thus, the number } \\
\text { of axes of the scale was three } \\
\text { represented in (communication }\end{array}$} & \multicolumn{3}{|c|}{$\begin{array}{l}\text { others) .The necessary } \\
\text { modifications were made by } \\
\text { the experts with deleting the } \\
\text { axes "recognition of the role } \\
\text { and its representation, and axis } \\
\text { of symbols with significance", } \\
\text { and this is evident in the final } \\
\text { version of the form( annex 8). } \\
\text { Preparation of the phrase of } \\
\text { the social interaction scale: }\end{array}$} \\
\hline
\end{tabular}
/ expectation / taking care of 
In the light of the achievement of the objective of the research, and depending on the aspect of scientific references, research and studies, the design of the form phrases have been taken into account to lead to accurate data and the phrases and should be simple, easy, and understandable and formulated in a proper linguistic way. They shouldn't be complex as they shouldn't carry more than one meaning, don't cause overlap and achieve the goal for which they were developed. The researchers drafted the social interaction scale in its initial form (annex 9) and presenting it on experts on $28 / 1 / 2016$. It reached (45) phrases and there were (16) phrases at the axis of communication, (15) phrases at the prediction axis, (14) phrases at the taking care of others axis.

The following points were taken into account in formulating the phrases:

A. Each phrase should measure a particular outcome linked to the main axis.

B- They should be comprehensive, accurate, clear; simple. Table (9) illustrates this:

Table (10) shows

Percentages of experts' opinions on the phrases of the Social interaction Scale

\begin{tabular}{c|c|c|c|c|c}
\hline \hline $\mathrm{S}$ & \multirow{2}{*}{ axes } & \multicolumn{2}{|c|}{ Phrases } & Phrases & $\begin{array}{c}\text { Proportional } \\
\text { numnificance }\end{array}$ \\
\cline { 3 - 6 } & & main & omitted & number & signe. \\
\hline \hline 1 & Communication & 16 & 2 & 14 & $36.84 \%$ \\
\hline 2 & Prediction & 15 & 3 & 12 & $31.57 \%$ \\
\hline 3 & $\begin{array}{c}\text { Taking care of } \\
\text { Others }\end{array}$ & 14 & 2 & 12 & $31.57 \%$ \\
\hline \hline
\end{tabular}

It is clear from table (9) that seven phrases were excluded according to the percentage of experts' opinions about the phrases of the scale. Thus, the number of phrases of the social interaction scale is (38) (annex 10).
Scientific coefficients of scale:

First: validity: the form was validated in several ways via: -The validity of the peer reviewers:

The form has been presented to ten experts at the Faculties of Physical education 
and faculties of education (annex 1) in order to poll their opinions on; the validity of this form regarding its suitability for students in terms of the clarity and integrity of phrases and formulation, in addition to making sure of the phrases and suitability with the objective of the form, with deleting, or modifying or adding what they see appropriate of phrases . The number of form phrases was (45)as it is shown in annex (9). The percentage of experts'opinions about the correct phrases of the form has been calculated as shown at table (11):

\section{Table (11) shows}

Percentages of social interaction scale phrases By experts' opinions $(n=10)$

\begin{tabular}{|c|c|c|c|c|c|}
\hline \multicolumn{2}{|c|}{ Communication axis } & \multicolumn{2}{|c|}{$\overline{\text { Prediction axis }}$} & \multicolumn{2}{|c|}{$\begin{array}{c}\text { Taking care of } \\
\text { Others axis }\end{array}$} \\
\hline $\begin{array}{l}\text { Phrase } \\
\text { No. }\end{array}$ & percentage & $\begin{array}{c}\text { Phrase } \\
\text { No. }\end{array}$ & Percentage & $\begin{array}{c}\text { Phrase } \\
\text { No. }\end{array}$ & percentage \\
\hline 1 & $90 \%$ & 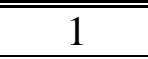 & $100 \%$ & 1 & $100 \%$ \\
\hline 2 & $100 \%$ & 2 & $90 \%$ & 2 & $90 \%$ \\
\hline 3 & $80 \%$ & 3 & $80 \%$ & 3 & $80 \%$ \\
\hline 4 & $90 \%$ & 4 & $80 \%$ & 4 & $80 \%$ \\
\hline 5 & $80 \%$ & 5 & $90 \%$ & 5 & $90 \%$ \\
\hline 6 & $90 \%$ & 6 & $100 \%$ & 6 & $100 \%$ \\
\hline 7 & $90 \%$ & 7 & $70 \%$ & 7 & $70 \%$ \\
\hline 8 & $100 \%$ & 8 & $80 \%$ & 8 & $80 \%$ \\
\hline 9 & $100 \%$ & 9 & $80 \%$ & 9 & $80 \%$ \\
\hline 10 & $70 \%$ & 10 & $70 \%$ & 10 & $70 \%$ \\
\hline 11 & $70 \%$ & 11 & $90 \%$ & 11 & $90 \%$ \\
\hline 12 & $80 \%$ & 12 & $80 \%$ & 12 & $80 \%$ \\
\hline 13 & $80 \%$ & - & - & - & - \\
\hline 14 & $100 \%$ & - & - & - & - \\
\hline \multicolumn{3}{|c|}{$\begin{array}{l}\text { It is obvious from Table } \\
\text { (11) that the percentage of } \\
\text { experts opinions ranged from } \\
70 \% \text { to } 100 \% \text {, and this } \\
\text { indicates the validity of the }\end{array}$} & \multicolumn{3}{|c|}{$\begin{array}{l}\text { content of the of the social } \\
\text { interaction scale phrases. } \\
\text {-Internal consistency } \\
\text { validity: } \\
\text { The researchers applied } \\
\text { the scale on } 28 / 2 / 2016 \text { on a }\end{array}$} \\
\hline \multicolumn{4}{|c|}{ Assiut Journal For Sport Science Arts } & & \\
\hline
\end{tabular}


poll group consisting of ten Students to measure the social interaction of the university year (2016-2017) from outside the basic research sample in order to obtain accurate answers to the following:

-The clarity of the scale phrases to the students.

-Difficulties facing students when answering the scale paragraphs.
-Knowing the time it takes for each student to answer the scale paragraphs.

The correlation coefficients among the phrases and their axes and the correlation coefficients between the axes and the total score of the scale are calculated as shown in table (12):

Table (12) shows

correlation coefficients between the phrases of the axes and the total score of the axis $(n=10)$

\begin{tabular}{c|c|c|c|c|c}
\hline \multicolumn{2}{c}{ Communication axis } & \multicolumn{2}{c|}{ Prediction axis } & \multicolumn{2}{c}{$\begin{array}{c}\text { Taking care of } \\
\text { Others axis }\end{array}$} \\
\hline $\begin{array}{c}\text { Phrase } \\
\text { No. }\end{array}$ & $\begin{array}{c}\text { Correlation } \\
\text { coefficient }\end{array}$ & $\begin{array}{c}\text { Phrase } \\
\text { No. }\end{array}$ & $\begin{array}{c}\text { Correlation } \\
\text { coefficient }\end{array}$ & $\begin{array}{c}\text { Phrase } \\
\text { No. }\end{array}$ & $\begin{array}{c}\text { Correlation } \\
\text { coefficient }\end{array}$ \\
\hline \hline 1 & $0.69^{*}$ & 1 & $0.65^{*}$ & 1 & $0.61^{*}$ \\
\hline 2 & $0.51^{*}$ & 2 & $0.96^{*}$ & 2 & $0.69^{*}$ \\
\hline 3 & $0.64^{*}$ & 3 & $0.61^{*}$ & 3 & $0.61^{*}$ \\
\hline 4 & $0.64^{*}$ & 4 & $0.58^{*}$ & 4 & $0.58^{*}$ \\
\hline 5 & $0.55^{*}$ & 5 & $0.51^{*}$ & 5 & $0.69^{*}$ \\
\hline 6 & $0.74^{*}$ & 6 & $0.61^{*}$ & 6 & $0.61^{*}$ \\
\hline 7 & $0.61^{*}$ & 7 & $0.58^{*}$ & 7 & $0.78^{*}$ \\
\hline 8 & $0.58^{*}$ & 8 & $0.82^{*}$ & 8 & $0.52^{*}$ \\
\hline 9 & $0.66^{*}$ & 9 & $0.71^{*}$ & 9 & $0.74^{*}$ \\
\hline 10 & $0.78^{*}$ & 10 & $0.69^{*}$ & 10 & $0.93^{*}$ \\
\hline 11 & $0.74^{*}$ & 11 & $0.52^{*}$ & 11 & $0.58^{*}$ \\
\hline 12 & $0.76^{*}$ & 12 & $0.93^{*}$ & 12 & $0.52^{*}$ \\
\hline 13 & $0.85^{*}$ & - & - & - & $0.61^{*}$ \\
\hline 14 & $0.52^{*}$ & - & - & - & $0.69^{*}$ \\
\hline \hline
\end{tabular}

The value of (r) table at (0.05) level $=(0.497)$

Table (12) shows that there is a statistically significant correlation at $(0.05)$ level between the score of the phrases in the axis and the overall score of the axis, and 
this indicates the validity of internal consistency.

Table (13)

Correlation coefficient values between each axis and the total score of scale $n=(10)$

\begin{tabular}{c|c}
\hline Axes & $\begin{array}{c}\text { Pearson's correlation } \\
\text { coefficient }\end{array}$ \\
\hline \hline First axis: Communication & $0.66^{*}$ \\
\hline Second axis: Prediction & $0.70^{*}$ \\
\hline Third axis: Taking care of Others & $0.66^{*}$ \\
\hline Scale as a whole & $0.74^{*}$ \\
\hline \hline
\end{tabular}

The value of (r) table at $(0.05)$ level $=(0.497)$

Table (13) shows that there is a statistically significant correlation at (0.05) level between the scale axes and the scale as a whole, and this indicates the validity of internal consistency.

Second: Stability of the scale:

The method of stability of Alpha Kronbach:

The social interaction scale was applied on 18/2/2016 upon an exploratory sample consisting of ten students from the research community and outside the basic sample of research to find the stability coefficient via the method of

Table (14) shows alpha as shown in table (14):

Stability Coefficient by Alpha Kronbach method for the scale of social interaction

\begin{tabular}{c|c|c}
\hline \hline $\mathbf{S}$ & Axes & $\begin{array}{c}\text { Pearson's correlation } \\
\text { coefficient }\end{array}$ \\
\hline \hline 1 & First axis: Communication & 0.57 \\
\hline 2 & Second axis: Prediction & 0.75 \\
\hline 3 & Third axis: Taking care of Others & 0.64 \\
\hline 4 & Scale as a whole & 0.65 \\
\hline \hline & It is clear from Table this indicates the stability of \\
(13) that the values of the the scale.
\end{tabular}
stability coefficient of the scale ranges from 0.57 to 0.65 , and

The method of reapplication: 
The two researchers applied the social interaction scale on 18/2/2016 upon an exploratory sample consisting of ten students from the research community and outside the basic sample of research, and reapplication was carried out after two weeks on $3 / 3 / 2016 \mathrm{~m}$ and the correlation coefficient between the two applications was done as shown in table(15):

\section{table (15) shows}

Pearson coefficient between the two applications for social interaction scale

\begin{tabular}{c|c|c}
\hline \hline $\mathbf{S}$ & Axes & $\begin{array}{c}\text { Pearson coefficient } \\
\text { values }\end{array}$ \\
\hline \hline & The first axis : communication & 0.63 \\
\hline & The second axis: prediction & 0.84 \\
\hline & Third Axis: taking care of others & 0.75 \\
\hline & Scale as a whole & 0.74 \\
\hline \hline
\end{tabular}

It is clear from table (15) that there is increase of the stability coefficient between the two applications as the values ranged from $(0,63-0$, 84), and this refers to the acceptance of the tool to be applied.

-Grades estimates and correction method:

Grades $(1,2,3)$ are placed to correspond to the ranking (agree - to some extent - don't agree) with the attitude toward social interaction, and the grades (1-2-3) with the attitude toward the lack of social interaction. The multiple grades are combined plus the phrases of each axis to give the axis score. The total mark of the scale consists of the score of the marks of the three axes of the scale, so that the highest score can be obtained in the scale is (114) and the lowest mark is (38) as shown in table (14): 
Triple estimation measure of the social interaction scale

\begin{tabular}{c|c|c|c}
\hline S & Agree & $\begin{array}{c}\text { To some } \\
\text { extent }\end{array}$ & $\begin{array}{c}\text { Do not } \\
\text { agree }\end{array}$ \\
\hline \hline Phrases in the direction of the dimension & 3 & 2 & 1 \\
\hline Phrases in the opposite of the dimension & 1 & 2 & 3 \\
\hline \hline
\end{tabular}

Defining the Scale time:

The two researchers determined the appropriate time to answer the scale in light of the results of the application on ten students enrolled at Faculty of Physical Education, New Valley branch, Assiut University and outside the basic sample of research from of the following equation:

Scale time $=\underline{\text { time spent by the }}$ first student $(15 \mathrm{~m})+$ time spent by last student $(25 \mathrm{~m})$

Therefore, the total time of the scale was (20) minutes .

\section{Exploratory studies:}

The first exploratory experiment:

The two researchers applied the questionnaire form related to the two scales : sportive culture related to educational environment and social interaction on Sunday $15 / 2 / 2016$, on a sample of ten students enrolled at the third and fourth grade( teaching specialization) oustside the research basic sample in order to know the suitability of the two scales for the research sample and the time it takes and the most important difficulties that the two researchers may face.

The Second exploratory experiment:

The two researchers applied the questionnaire form related to the two scales : sportive culture related to educational environment and social interaction on the basic sample of sixty students enrolled at the third and fourth grade( teaching specialization) through the period from $13 / 3 / 2016$ to Monday 28/3/2016.

\section{The Main experiment:}

The two researchers conducted the main experiment applied the form related to the scale of the sportive and environment culture and the scale of social interaction on the basic research sample whose individuals are sixty 
students who are enrolled at the third and fourth grades (teaching specialization) during the period from Sunday 3/4/2016 till Monday 18/4/2016.

\section{The Research Statistical} Processing:

The data obtained from the measurements for the Research Experiment (research sample) to do the statistical processing were uploaded, and it is represented in:Arithmetic mean-standard deviationcoefficient of alpha cronbachpercentage of correlation coefficient - $\mathrm{T}$ test for differences significance. The two researchers have used the SPSS program to process data statistically. The grades have been rounded to the nearest two decimal digits. The two researchers have been satisfied with a tabular significant value at a significance level (0.05).

\section{Findings and Discussion:}

Table (17)

Arithmetic mean, standard deviation, differences significance and $T$ - value among male and female students in the level of sportive culture related to educational environment $n=(60)$

\begin{tabular}{|c|c|c|c|c|c|c|c|}
\hline \multirow[t]{2}{*}{$\overline{\mathbf{S}}$} & \multirow{2}{*}{$\begin{array}{l}\text { The axes } \\
\text { of sportive } \\
\text { culture } \\
\text { scale }\end{array}$} & \multicolumn{2}{|c|}{ Students(F) } & \multicolumn{2}{|c|}{ Students(M) } & \multirow{2}{*}{$\begin{array}{c}\text { Differences } \\
\text { among } \\
\text { means }\end{array}$} & \multirow{2}{*}{$\begin{array}{c}\text { The } \\
\text { calculated } \\
\text { T value } \\
\text { and its } \\
\text { significance }\end{array}$} \\
\hline & & mean & $\begin{array}{l}\text { Standard } \\
\text { deviation }\end{array}$ & Mean & $\begin{array}{l}\text { Standard } \\
\text { deviation }\end{array}$ & & \\
\hline$\overline{1}$ & $\begin{array}{l}\text { The first axis } \\
: \text { sportive } \\
\text { aspect }\end{array}$ & 64.70 & 2.24 & 70.87 & 4.24 & 6.17 & 2.67 \\
\hline 2 & $\begin{array}{l}\text { The second } \\
\text { axis: } \\
\text { environmental } \\
\text { aspect }\end{array}$ & 47.46 & 3.08 & 56.10 & 3.11 & 8.64 & 2.78 \\
\hline 3 & $\begin{array}{l}\text { Third Axis: } \\
\text { Health aspect }\end{array}$ & 47.20 & 2.93 & 52.90 & 3.76 & 5.70 & 1.92 \\
\hline 4 & $\begin{array}{l}\text { Fourth Axis } \\
\text { :educational } \\
\text { aspect }\end{array}$ & 46.46 & 2.82 & 53.63 & 3.32 & 7.17 & 1.71 \\
\hline
\end{tabular}

$\mathrm{T}$ Value at a significance level $(0.05)=(1.3)$

It is clear from table (17) male students and female that there is statistically students in the level of sportive significant differences between culture related to educational the average of the grades of environment in favor of male 
students, as the calculated $\mathrm{T}$ value is greater than the tabular $\mathrm{T}$ value at an attribute level (0.05).

(Male students, female students, sportive aspect, environmental aspect, healthy aspect, educational aspect)

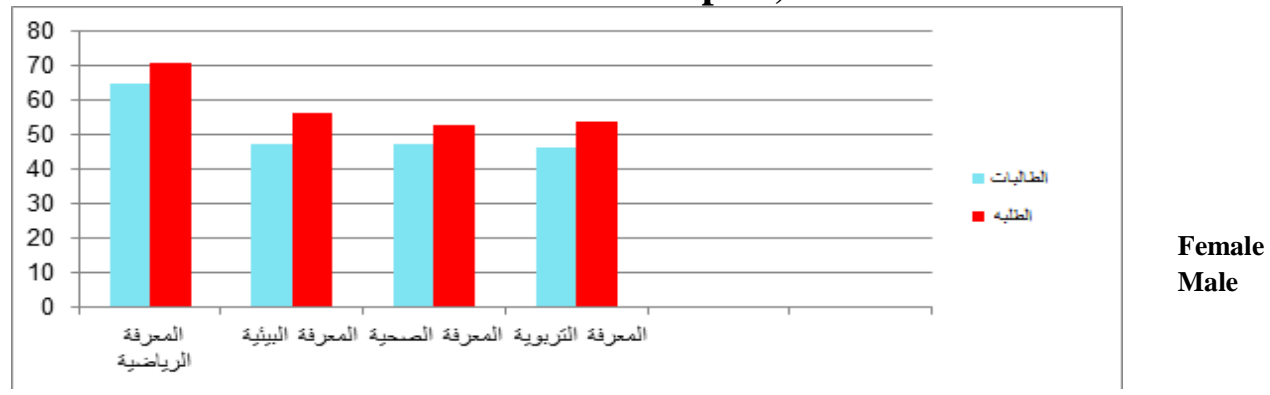

Figure (1)

Male and female students at the scale of sportive culture related to educational environment

Table (18)

mean, standard deviation, differences significance and $T$ value among male and female students in the level of social interaction $n=(60)$

\begin{tabular}{|c|c|c|c|c|c|c|c|}
\hline \multirow[t]{2}{*}{$\mathbf{S}$} & \multirow{2}{*}{$\begin{array}{l}\text { The axes of } \\
\text { social } \\
\text { interaction } \\
\text { scale }\end{array}$} & \multicolumn{2}{|c|}{ Pre measure } & \multicolumn{2}{|c|}{ Post measure } & \multirow{2}{*}{$\begin{array}{l}\text { Differences } \\
\text { among } \\
\text { means }\end{array}$} & \multirow{2}{*}{$\begin{array}{c}\text { The } \\
\text { calculated } \\
\text { T value } \\
\text { and its } \\
\text { significance }\end{array}$} \\
\hline & & mean & $\begin{array}{l}\text { Standard } \\
\text { deviation }\end{array}$ & Mean & $\begin{array}{l}\text { Standard } \\
\text { deviation }\end{array}$ & & \\
\hline 1 & $\begin{array}{l}\text { The first axis : } \\
\text { communication }\end{array}$ & 63.47 & 3.33 & 68.43 & 5.65 & 4.96 & 2.45 \\
\hline 2 & $\begin{array}{c}\text { The second } \\
\text { axis: prediction }\end{array}$ & 52.63 & 4.51 & 57.63 & 8.22 & 5.00 & 2.07 \\
\hline 3 & $\begin{array}{l}\text { Third Axis: } \\
\text { taking care of } \\
\text { Others }\end{array}$ & 44.50 & 3.36 & 47.40 & 4.55 & 2.90 & 2.26 \\
\hline
\end{tabular}

$\mathrm{T}$ Value at a significance level $(0.05)=1.69$

It is clear from table (18) interaction in favor of male that there is statistically students, as the calculated $\mathrm{T}$ significant differences between the average of the grades of male students and female students in the level of social value is greater than the tabular $\mathrm{T}$ value at an attribute level (0.05). 


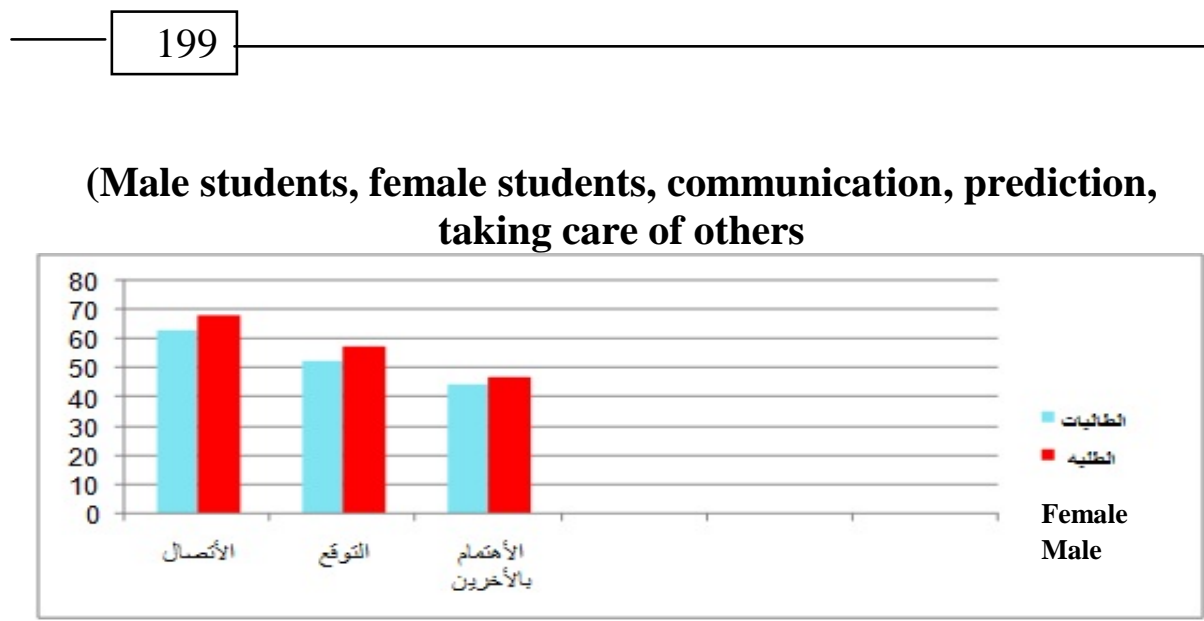

Figure (2)

Male and female students at the scale of social interaction

Table (19)

Correlation coefficient between the level of sportive culture

related to educational environment and social interaction $\mathbf{n}=(60)$

\begin{tabular}{c|c|c|c|c|c|c}
\hline $\begin{array}{c}\text { Social } \\
\text { interaction/ } \\
\begin{array}{c}\text { Sportive culture } \\
\text { related to } \\
\text { educational } \\
\text { environment }\end{array}\end{array}$ & Communication & Prediction & $\begin{array}{c}\text { Taking } \\
\text { care of } \\
\text { others }\end{array}$ & total & $\begin{array}{c}\text { The } \\
\text { calculated } \\
\text { r value and } \\
\text { its } \\
\text { significance }\end{array}$ & $\begin{array}{c}\text { The table r } \\
\text { value and } \\
\text { its } \\
\text { significance }\end{array}$ \\
\hline \hline $\begin{array}{c}\text { sportive } \\
\text { aspect }\end{array}$ & 14 & 5 & 4 & 23 & 0,496 & \\
\hline $\begin{array}{c}\text { environmental } \\
\text { aspect }\end{array}$ & 7 & 6 & 4 & 17 & \multirow{2}{*}{0,21} \\
\hline Health aspect & 5 & 3 & 2 & 10 & \\
\hline $\begin{array}{c}\text { educational } \\
\text { aspect }\end{array}$ & 6 & 2 & 2 & 10 & & \\
\hline Total & 32 & 16 & 12 & 60 & \\
\hline \hline
\end{tabular}

$\mathrm{R}$ value at significance level $(0.05)=0.21$

It is clear from table (19) that there is a correlation between the level of sportive culture related to educational environment and its relationship to the social interaction (place of research). where The calculated $(\mathrm{r})$ value was (0.496) and it is greater than the tabular $r$ value at the level of "0.05", and this indicates the relational relationship between the two variables and the positive impact of sportive culture related to educational 
environment on social interaction.

Discussion of the results: Discussion of the first hypothesis findings:

It is clear from table 17 that there are statistically significant differences between male and female students in the level of sportive culture related to educational environment in favor of the male students and the two researchers believe that this result may be due to the interest of male students at the Faculty of Physical Education to watch sportive games and local and global events as well as different educational programs. Unlike the female students who prefer watching the drama works to watching sportive clearly. This, in turn, may affect their cultural sportive knowledge. The male Students practice sportive activity and exercise on different games before joining the faculty of Physical Education in a way that is greater than the female students due to the nature of the new Valley community and its customs like the rest of the governorates of Upper Egypt.This is consistent with the results of the studies of
Shane (Chen) (2010) (18)\& Frasser (2009) (19) which referred to the point that there are statistically significant differences in the sportive identity between male and females in favor of males.

Thus, the validity of the first hypothesis is achieved "there are statistically significant difference in the level of sportive culture related to educational environment among the male and females students of the faculty of Physical education, the new Valley branch, Assiut University.

Discussion of the second hypothesis findings:

It is clear from table (18) that there are statistically significant differences among male and female students in the level of social interaction in favor of male students. The researchers date this result back to the point that the previous experience of male students about sportive culture is greater and clearer than it for female students. This may affect their active participation in the field of interaction as sports has a social role in the development of the values of cooperation, initiative and 
community participation that appear in the behavior of sports persons in a positive manner in participating in various societal issues.This is in accordance with the results of the studies of Shane (Chen) (2010) (18)\& Frasser (2009) (19).It was resulted from these studies that commitment of the first group hich is characterized by the specialized sportive background is better than it is for the second group. It was revealed that there are statistically significant differences among male and female students in favor of males. It can be said that the validity of the second hypothesis is achieved "there are statistically significant differences in the level of social interaction among male and female students at the Faculty of Physical Education, New Valley branch, Assiut University.

Discussion of the third hypothesis findings:

It is clear from table (19) that there are statistically significant differences between the sportive culture related to educational environment level and the social interaction degree for male and female students at the Faculty of Physical Education, New Valley branch, Assiut university. The researchers date this result back to the point that the more the sportive culture related to educational environment increases, the more social interaction is developed among students. The increase in the level of the sportive culture related to educational environment helps in creating the student's cultural thought, increases his self-confidence develops the positive attitudes for him toward the environment and community, and this is reflected in his cooperative behavior and participation at issues regarding the surrounding environment. Not only the development of the sportive cultural level related to educational environment level affects the physical aspect of the individual, but it affects positively the psychological, behavioral and intellectual aspects as well .This accords with the results of the studies of Muhammad Hosni (2016) (15) which stated that sportive culture enhances the values of national loyalty for young juveniles. The study of Honda 
Ali (2013) (17) refered to the statistically

significant correlational relation between social interaction and achievement for the third grade of preparatory school students. The study of Salah M. Abdul Baset (2010) (7) stated that the program of sportive activity and the suggested healthy culture improved the fitness level related to health and increase of healthy behavior for the sample.. It can be said that the validity of the third hypothesis is achieved "there are statistically significant differences between the level of the sportive culture related to educational environment and social interaction for the students at the Faculty of Physical Education, New Valley branch, Assiut University.

\section{Conclusions:}

In the light of the nature, objectives, hypotheses, methodology and Sample nature of research, in addition to the statistical analysis of data, the following conclusions were reached out:

There is improvement in the level of sportive culture related to educational environment for male students, which is higher than it for female students at the Faculty of Physical Education, the new Valley branch, Assiut university.

There is improvement in the level of social interaction for male students, which is higher than it for female students at the Faculty of Physical Education, the new Valley branch, Assiut university.

There is a direct correlation between the level of sportive culture related to educational environment and the social interaction for the students at the Faculty of Physical Education, New Valley branch, Assiut University.

\section{Recommendations:}

Based on the findings of the research, the researchers recommend the following:

\section{Giving interest} to improving the level of sportive culture related to educational environment among students through various academic courses and through the activities carried out by the competent committees of the college.

Paying attention to improving the level of social interaction through the 
attendance of students to the college camps and specialized workshops that help students to form positive values toward interacting with community issues.

Paying great attention to the level of sportive culture for female students because of the apparent lack among them due to the nature of the local community in the New Valley.

References:

1- Ikhlas Mohamed Abdel Hafeez, Mustafa Hussain Bahy: "Sportive sociology ", Book Center for Publishing, Cairo, 2001.

2- Ikhlas Mohamed Abdel Hafeez, Mustafa Hussain Bahy: "Methods of scientific research in the fields of education, psychology and sports, Book Center for Publishing, $2^{\text {nd }}$ Floor, Cairo, 2002.

3- Elsayed Elsayed Saeed Abu Saoud: "A proposed program of environmental culture for students at the Faculty of Physical Education, Mansoura University, 2010.

4- Ahmed Zaki Badawy: "Glossary of social Sciences", Lebanon Publishing Library, Beirut, 1978.

5- Hosni Mohammed Ibrahim: "The impact of the school environment on the trends of pupils in the basic education stage" thesis, Institute of Environmental Studies and research, Ain Shams University, 2001.

\section{6- Hussein Ahmed el-Shafei:} Physical Education and environmental law, I, library and El-eshaa el-fani Press, Alexandria, 2001.

7- Salah Mohammed Abdul Baset Mohamed: "The effectiveness of a program of sportive activity and health culture on the physical fitness and health behavior of juvenile delinquents in Assiut governorate ",Faculty of physical Education for boys, Banha University, 2010.

\section{8- Osman Mahmoud Shahad:}

"The impact of watching sportive satellite channels in the dissemination of sportive culture among students of Deyale University" Master thesis, Faculty of Physical Education, University of Deyale, 2009.

9- Afaf Osman, Fadia Rashad, Mostafa Kamel: "Lights on the curricula of physical *education" Dar alWafa Printing and Publishing, Alexandria, 2007.

10- Ghassan Mohammed Sadiq: "Principles of education and Physical Education " Dar al-Hekma for printing and Publishing, Baghdad, 1990. 
11- Fadi Fattouh Abdo: "The impact of an educational program using the introductory games on the level of performance of some basic skills and motor abilities and their relationships to the psychological and social compatibility of football Buds", M.A. thesis, Faculty of Physical Education, Mansoura University, 2011.

12- Qasim Ali al-Sarraf: "Measurement and evaluation in education ", Modern book House, Cairo, 2004.

13- Mohammed AlSayed Khalil, Ahmad Abdulazeem Abdulla: "Kinetic education between Theory and practice", Al Amal Offset Press, Mansoura, 3, 2003.

14- Mohammed Hosni Zainal Abidin Ahmed: " The impact of sportive culture on promoting the values of national affiliation in juvenile delinquents $\mathrm{PhD}$ thesis, Faculty of Physical Education for boys, Banha University, 2016.

15- Mohammed Saad Zaghloul, Wafa Mohammed Kamal: "The impact of a proposed program for expressive movements on Modification of trends towards the environment among pupils of the first cycle of basic education, International Educational Conference, 1999.
16- Mohammed Sobhi Hasaneen: "Measurement and evaluation in physical education " Arab thought house for Publishing, Cairo, 4th, $2000 \mathrm{~m}$

17- Honda Ali Ali: "Social interaction and its relationship to the academic achievement of some secondary school students." Master's thesis, Faculty of Humanities and Social Sciences, Mohammed Khider University, Biskra, Algeria, 2013.

18- Chen, S., Synder, S., \& Magenr, M.The effects of sport participation on studentathletes' and non-athlete students' social life and identity. Journal of issues in intercollegiate athletics, 3, 2010, 176-1

19- Fraser, L., Fogarty. G., \& Albio, M. Levels of athletic identity among elite Australian athletes: The impact of gender: age and career status. Abstracts I Journal of science and medicine in sport, 12(1), 2009, 79- 80.

Martin, Peter: Teacher qualification guidelines, Ecological Culture,2008.

20- Under Wood, G.L1: The Physical Education Curriculum in the secondary school planning implementation, the falmer press Dover,1993. 